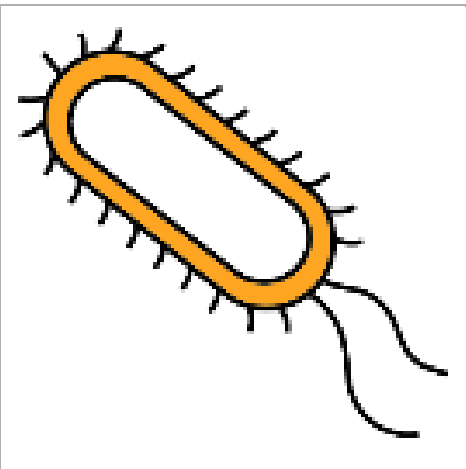

OCT 27, 2020

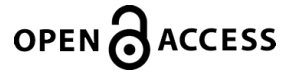

DOI:

dx.doi.org/10.17504/protocol s.io.bdr2i58e

Protocol Citation: Cristina Hernandez Rollan, Kristoffer Bach Falkenberg, Maja Rennig, Andreas Birk Bertelsen, Morten Norholm 2020. Protein expression and extraction of hard-to-produce proteins in the periplasmic space of Escherichia coli. protocols.io

https://dx.doi.org/10.17504/p rotocols.io.bdr2i58e

License: This is an open access protocol distributed under the terms of the Creative Commons Attribution License, which permits unrestricted use, distribution, and reproduction in any medium, provided the original author and source are credited

Protocol status: Working We use this protocol and it's working

Created: Mar 16, 2020

Last Modified: Oct 28, 2020

PROTOCOL integer ID:

34330

\section{(3) Protein expression and extraction of hard-to-produce proteins in the periplasmic space of Escherichia coli}

5 In 1 collection

\section{Cristina Hernandez Rollan ${ }^{1}$, Andreas Birk \\ Maja Rennig ${ }^{1}$, Bertelsen ${ }^{1}$, \\ ${ }^{1}$ Technical University of Denmark}<smiles>C1CCCCCC1</smiles>

Cristina Hernandez Rollan

\author{
Kristoffer Bach Falkenberg ${ }^{1}$, \\ Morten \\ Norholm ${ }^{1}$
}

\section{ABSTRACT}

E. coli is a gram-negative bacteria used mainly in academia and in some industrial scenarios, as a protein production workhorse. This is due to its ease of manipulation and the range of genetic tools available.

This protocol describes how to express proteins in the periplasm E. coli with the strain BL21 (DE3) using a T7 expression system. Specifically, it describes a series of steps and tips to express "hard-to-express" proteins in E. coli, as for instance, LPMOs.

The protocol is adapted from Hemsworth, G. R., Henrissat, B., Davies, G. J., and Walton, P. H. (2014) Discovery and characterization of a new family of lytic polysaccharide monooxygenases. Nat. Chem. Biol.10, 122-126.

\section{GUIDELINES}

The periplasm of $E$. coli is often the preferred strategy to produce heterologous proteins in this bacterium as it provides the means for disulfide bond formation. The choice of the signal peptide is of great importance to ensure correct and efficient translocation to the periplasm. In our lab, we routinely screen five different signal peptides: MalE ${ }^{\mathrm{SP}}, \mathrm{OmpA}^{\mathrm{SP}}, \mathrm{PhoA}^{\mathrm{SP}}, \mathrm{DsBA}^{\mathrm{SP}}$, and PelB${ }^{\mathrm{SP}}$. 
Keywords: LyGo, LPMO, Periplasmic expression, E. coli, protein expression, Periplasmic extraction

\section{MATERIALS}

MATERIALS

\section{$8 \%$} BL21(DE3) Competent E.coli - 6x0.2 ml New England Biolabs Catalog \#C25271

80 IPTG Bio Basic Inc. Catalog \#IB0168.SIZE.100g

88 EDTA Fisher Scientific Catalog \#16 004Y

88 Kanamycin Research Products International (rpi) Catalog \#K22000-25.0

88 LB Research Products International (rpi) Catalog \#L24400-2000.0

88 Sucrose Fisher Scientific Catalog \#S25590B

89 Trizma® base Merck Millipore Sigma Catalog \#93362

\section{SAFETY WARNINGS}

(1) This protocol describes the construction of GMO classified organisms. Make sure that the local GMO and safety legislations are respected.

\section{BEFORE START INSTRUCTIONS}

Prepare a fresh transformation of your expression vector in E. coliBL21 DE3 cells.

\section{Pre culture - Day 1}

1 Pick a fresh colony of your BL21 (DE3) strain with your expression vector, and inoculate it in LB supplemented with relevant antibiotics. Grow the culture at $837^{\circ} \mathrm{C}$ at 250 RPM shaking Overnight. The volume of the overnight culture depends on the volume of the expression culture and should be at least $1 / 100$ of the expression culture

\section{Inoculation, Induction and expression - Day 2}

2 Dilute the overnight culture 1:100 in fresh LB supplemented with relevant antibiotics

3 Grow the culture at $837^{\circ} \mathrm{C}$ with 250 RPM shaking until an $\mathrm{OD}_{600}=0.5-0.6$ 
4

Move the culture into an incubator set to $18{ }^{\circ} \mathrm{C}$ with 180 RPM of shaking and grow the culture to $\mathrm{OD}_{600}=0.8-1.0$

5 Induce the expression by adding IPTG to a final concentration of [M] 1 millimolar (mM)

6 Let the culture grow at $8^{\circ} 18^{\circ} \mathrm{C}$ with 180 RPM shaking for $20: 00: 00$ Note

Expression at low temperatures is recommended to enhance the solubility of some proteins.

\section{Harvesting and periplasmic extraction - Day 3}

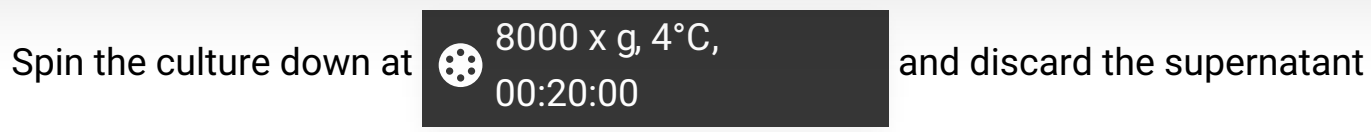

Note

Remove as much of the remaining liquid as possible from the centrifuge tube. This helps greatly in periplasmic extraction.

8 Resuspend the pellet in $\triangle 3 \mathrm{~mL}$ of buffer TSE buffer (200 mM Tris- $\mathrm{HCl}$ pH 8, 500mM sucrose, $1 \mathrm{mM}$ EDTA) per gram of cells (this normalization can also be based on $\mathrm{OD}_{600}$ where $\triangle 12 \mu \mathrm{L}$ TSE per OD Unit is added)

Note

Carefully resuspend the cells in the TSE buffer to avoid breaking the cells. A good tip is to use a sterile inoculation plastic loop to resuspend the pellet in the buffer before using a pipette tip. 
9 Incubate the suspension at $8^{\circ}$ Room temperature for $00: 10: 00$

10 Cold-shock the cells by adding $\triangle 3 \mathrm{~mL}$ of ice-cold sterile MQ water per gram of cells (or alternatively, $\triangle 12 \mu \mathrm{L}$ of ice-cold water per every $\mathrm{OD}_{600}$ Unit can be added).

11 Incubate the suspension $\mathbb{8}^{\circ}$ On ice for 00:10:00

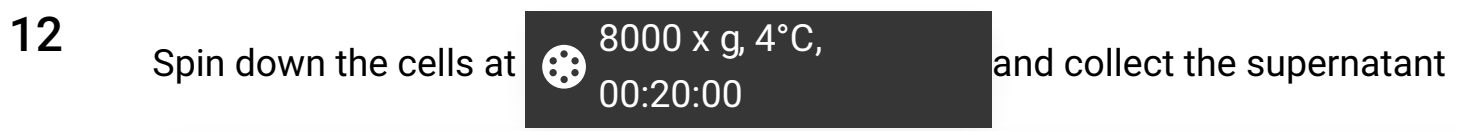
Note

The supernatant contains the periplasmic extraction

13 Keep the extraction $8^{\circ}$ On ice when working with it and at $8^{\circ} 4{ }^{\circ} \mathrm{C}$ for storage 